\title{
Rheological Analyses and Artificial Neural Network as Optimization Tools to Predict the Sensory Perception of Cosmetic Emulsions
}

\author{
Angélica Franzol ${ }^{a}$ (D), Thais Mancini Banin ${ }^{b}$,Tayra Rodrigues Brazil ${ }^{a *}$ (D), Mirabel Cerqueira Rezende ${ }^{a}$ (D) \\ ${ }^{a}$ Universidade Federal de São Paulo, Instituto de Ciência e Tecnologia, São José dos Campos, SP, \\ Brasil. \\ ${ }^{b}$ Universidade Federal do ABC, Centro de Engenharia, Modelagem e Ciências Sociais Aplicadas \\ (CECS), Santo André, SP, Brasil.
}

Received: May 26, 2021; Revised: August 21, 2021; Accepted: August 25, 2021

\begin{abstract}
Pharmaceutical, cosmetic and personal care products are mainly based on emulsions and their rheological behavior can be a critical factor for successful use. Thus, rheological analysis is a promising tool, since the stability, sensory aspects and processing parameters can be assessed. This work presents the rheological analyses of 39 samples of emulsions and the use of data obtained in a tool based on artificial neural networks (ANN), in order to predict the sensory performance of cosmetic emulsions. The storage (G') and loss (G') moduli, yield stress and thixotropy were measured experimentally and used in the ANN model. The correlation of the results obtained in the simulations with sensory tests performed with consumers showed accuracy of $60-84 \%$. The reported results demonstrate that the prediction of sensory perception based on rheological analyses offers a very useful strategy for further studies and can support the development of new products in less time.
\end{abstract}

Keywords: Emulsion, Rheology, Prediction, Artificial neural network.

\section{Introduction}

Emulsions are of great importance in many applications, notably in the food industry (e.g., mayonnaise, ice cream, and milk) and in the production of coatings and cosmetics ${ }^{1-3}$. Emulsions are polyphase systems composed of a dispersed or fragmented phase (bubbles, droplets or particles) within a continuous phase $\mathrm{e}^{4}$, where the size of the fragmented phase strongly influences the emulsion stability ${ }^{5,6}$, which can vary from minutes to years ${ }^{6-8}$. In this context, one of the main challenges in the development of cosmetic emulsions is achieving the desired stability and sensory parameters in terms of consumer perception.

Consumer perception is assessed by sensorial analysis conducted under controlled conditions, using appropriate tools and techniques in order to obtain consistent and reliable results $^{9-11}$. This type of analysis allows the attributes or global characteristics of a product to be evaluated through the five human senses, with the aim of measuring how the attributes are perceived by consumers ${ }^{3,12-16}$. The evaluation can be performed by analytical or affective methods. In the analytical methods, trained professionals define descriptive and discriminative aspects of the tested samples, outlining the sensorial profile of the product. In affective methods, potential consumers with no expertise on the subject evaluate samples and the results are based on their acceptance and preference in relation to the tested samples ${ }^{17}$.

The brain's ability to receive and process sensory information is defined as the perception of the individual, which plays a key role in the sensory evaluation of a product.

*e-mail: tayrabrazil@gmail.com
A sensory evaluation measures the physiological response to a stimulus, minimizing influences presented by psychological factors, such as culture, age and environmental aspects. The literature shows various studies involving sensory studies, for example, the main aspects involved in the consumers perception with different antiperspirants and deodorants (cream, aerosol, roll-on, and stick), comparing whether the concept of effectiveness by the consumer is explained only by the duration of the effect or if it integrates other components ${ }^{18}$. David et al. ${ }^{19}$ investigated the affective and brain effects of using a rose-scented cosmetic cream and observed that the scented cream over the odorless cream increased the positive affective states (more relaxation, satisfaction, happiness) and reduced reactivity associated with the threat and negative stimuli. Parente and Ares ${ }^{20}$ observed the effect of appearance (color and transparency) and fragrance of liquid hand soap on conceptual associations and expectations of consumers and observed the dependence of consumer liking with the fragrance. Already the pearly appearance did not influence liking but showed a significant effect on consumer expectations regarding functional aspects of the liquid hand soap.

To complement sensorial analysis, determining the rheological characteristics has shown to be important in the development and success of new formulations of emulsions ${ }^{5,11}$. Reports in the literature show that rheological profiles can aid the prediction of the stability of emulsions, together with the sensory expectation of consumers ${ }^{21-23}$. For example, rheological analysis based on frequency sweep can successfully predict the stability of emulsions under severe conditions of transport vibration up to the 
point of sale $\mathrm{e}^{24,25}$. Thus, considering concepts of thixotropy, viscosity, yield stress and frequency sweep can be very useful in determining primary and secondary sensory aspects ${ }^{26-28}$. The primary sensory aspects for skin creams are positive when the consumer feels a full-bodied product in contact with the skin before spreading. The secondary sensory aspects include a decrease in viscosity (perceived as consistency by the consumer) while the product is being spread, facilitating its application.

Thus, rheological analysis has proven to be a useful tool for evaluating the effect of stabilizers, used to minimize or prevent sediment or aggregate formation in dispersed liquid systems, and to assess the consistency of products, which is influenced by several factors, such as adhesion and cohesion forces, elasticity, viscosity, thixotropy and microstructure ${ }^{5,26-29}$. Despite the advantages of rheological analysis to investigate the stability and sensory aspects of cosmetic emulsions ${ }^{21,23,26}$, few studies in this area have been reported in the literature, highlighting the need for further research on this topic.

Artificial neural networks (ANNs) are relatively simple computational techniques which provide a mathematical model inspired by the structure of intelligent organisms. Some performance characteristics of the resulting information processing system are observed in biological neural networks, which acquire knowledge through experience $\mathrm{e}^{30-33}$. Thus, the main inspiration for ANNs was biological neural networks. An ANN is a massively parallel processor, comprised of simple processing units, which have a natural propensity to store experimental knowledge and make it available for use $^{30-34}$. This process is similar to the brain in two aspects: a) knowledge is acquired by the network by way of data from the environment, through a learning process, also known as the 'learning algorithm', which is aimed at adjusting the synaptic weights of the network in an ordered way to achieve the desired objective; and b) the connections between neurons (synaptic weights) are used to store the knowledge acquired ${ }^{35}$.

The objective of this study is to gain a better understanding of the sensorial perception of cosmetic emulsions, from a global perspective, by establishing a robust statistical model based on artificial neural networks with the aid of rheological data. To achieve this, rheological parameters, i.e., storage and loss moduli, yield stress and thixotropy properties, were measured and used in a simulation tool for predicting the sensory performance of several cosmetic emulsions.

Focusing on practical applications, this study aims provide important data to replace extensive studies involving sensory testing with human participants and to promote more competitive development processes with a reduced number of people exposed to chemicals and in shorter time. Effectively the methodology explored in this work can support new developments in cosmetics area, among others, boosting the introduction of new products into the market.

\section{Materials and Methods}

\subsection{Materials}

With the aim of broaden our understanding of the sensorial perception of cosmetic emulsions from a global perspective, through the employment of a robust statistical model, 39 samples were used in this work. These samples comprise sun protection products for body and face, produced by different manufacturers, available commercially in four different regions of the globe, that is, Asia, Europe, North America, and South America. Table 1 shows the samples used in this study, in alphabetic order. Since these are commercial samples and the manufacturers are identified, the formulas are not reported herein and they were randomly coded (Table 2), with no direct correlation with the order of products in Table 1. This procedure was adopted in order to preserve the characteristics of each product, without exposing possible details of the formulas and their respective manufacturers.

\subsection{Characterization}

\subsubsection{Rheological tests}

The rheological tests were carried out in a tension control rheometer (CS), manufactured by Haake, model Rheo Stress 6000 , with cone-plate sensors of $35 \mathrm{~mm}$ diameter, $2^{0}\left(\mathrm{C} 35 / 2^{\circ} \mathrm{Ti}\right)$, at $25^{\circ} \mathrm{C}$. The temperature control was carried out using a thermostat (RS6000 - Peltier TC81). Two types of rheological tests were carried out, one for the obtainment of the flow curves (stationary regime) and the other to determine the storage modulus $\left(\mathrm{G}^{\prime}\right)$ and the loss modulus (G"), in the oscillatory regime, with frequency sweep. The parameters employed in the tests under stationary regime (determination of the yield stress, viscosity and thixotropy) were: shear rate from 0 to $300 \mathrm{~s}^{-1}$, equilibrium time of $300 \mathrm{~s}$ and gap of $105 \mathrm{~mm}$. In the tests carried out in the oscillatory regime (frequency sweep with the determination of G' and G' as a function of frequency) the following parameters were applied: frequency 1 to $100 \mathrm{~Hz}$, scanning amplitude (oscillatory) 0.001 to 1.0 , equilibrium time $300 \mathrm{~s}$ and gap $105 \mathrm{~mm}$ and constant shear stress in the linear viscoelasticity region.

\subsubsection{Sensorial analysis}

The sensorial analysis of the samples was based on the affective method ${ }^{17}$. This procedure involved about 80 consumers from each global region included in the study, aided by the company Johnson \& Johnson. The consumers received randomly two samples of emulsion (from those listed in Table 1) and filled in a questionnaire to share their perception of use, taking into account 14 attributes of the product, which were related to general impression, consistency, spreadability, stickiness, product sensation on dry or oily skin, heavy or light and texture.

Consumer perception was classified in a range of 1 to 5. If well accepted, the product was classified as 5 and if the perception was very poor the sample received a score of 1 . This classification was based on the literature ${ }^{30}$. The responses were assessed with the aid of evaluation methods used in market research: Top Two Box (TTB) and Just About Right (JAR) ${ }^{36}$.

\subsection{Statistical model}

In this study, the statistical model based on artificial neural networks employed only a hidden layer, in accordance with the literature ${ }^{30-33}$, where the output variables (percentage of consumer acceptance) were dependent on the input 
Table 1. Samples of sun protection products used in this study.

\begin{tabular}{|c|c|c|c|c|}
\hline & Sample & $\begin{array}{l}\text { Type of } \\
\text { product }\end{array}$ & Region & Manufacturer \\
\hline 1 & Bioré Bright Milk FPS $50^{\circledR}$ & Body & \multirow{8}{*}{ Asia } & Kao Corporation \\
\hline 2 & Bioré Bright Milk FPS $50^{\mathbb{R}}$ & Face & & Kao Corporation \\
\hline 3 & Dr.Ci:Labo FPS50 $0^{\circledR}$ & Face & & Dr.Ci:Labo \\
\hline 4 & Dr.G Medi UV Ultra Sun FPS50 ${ }^{\circledR}$ & Face & & Dr.G Medi \\
\hline 5 & Natural Eco Sun FPS50 $0^{\circledR}$ & Face & & Natural Eco \\
\hline 6 & Neutrogena Ultra Sheer FPS50 ${ }^{\circledR}$ & Body & & $\begin{array}{c}\text { Johnson \& } \\
\text { Johnson (J\&J) }\end{array}$ \\
\hline 7 & Shiseido Perfect FPS50 Wet Force ${ }^{\circledR}$ & Body & & Shiseido \\
\hline 8 & Shiseido Anessa Perfect UV FPS50 ${ }^{\circledR}$ & Face & & Shiseido \\
\hline 9 & Garnier Ambre Solaire FPS30 ${ }^{\circledR}$ & Face & \multirow{9}{*}{ Europe } & L'Oreal \\
\hline 10 & La Roche Posay Anthelios Ultra Léger Spray FPS30 $0^{\circledR}$ & Milk & & L'Oreal \\
\hline 11 & Nivea Protect \& REfresh FPS30 $0^{\circledR}$ & Face & & Beiersdorf AG \\
\hline 12 & Nivea Sun Protect \& Hydrate Spray FPS30 ${ }^{\circledR}$ & Milk & & Beiersdorf AG \\
\hline 13 & Neutrogrena Aqualight FPS30 $0^{\circledR}$ & Face & & $\mathrm{J} \& \mathrm{~J}$ \\
\hline 14 & Neutrogrena Sun Fresh FPS30 $0^{\circledR}$ & Face & & $\mathrm{J} \& \mathrm{~J}$ \\
\hline 15 & Piz BUin MOisturing Sun Lotion FPS $30^{\circledR}$ & Face & & $\mathrm{J} \& \mathrm{~J}$ \\
\hline 16 & Piz Buin Ultra-light Dry Touch FPS30 & Milk & & $\mathrm{J} \& \mathrm{~J}$ \\
\hline 17 & Shiseido Expert Sun Aging Protection Lotion Plus FPS50+ ${ }^{\circledR}$ & Face & & Shiseido \\
\hline 18 & Anessa Perfect UV Sunscreen FPS50 $0^{\circledR}$ & Face & \multirow{12}{*}{$\begin{array}{c}\text { South } \\
\text { America }\end{array}$} & Shiseido \\
\hline 19 & La Roche Posay Anthelios Air Licium FPS30 $0^{\circledR}$ & Face & & L'Oreal \\
\hline 20 & La Roche Posay Anthelios Air Licium FPS70 ${ }^{\circledR}$ & Face & & L'Oreal \\
\hline 21 & Loreal Solar Expertise FPS50 ${ }^{\circledR}$ & Body & & L'Oreal \\
\hline 22 & Neutrogena Sun Fresh FPS50 $0^{\circledR}$ & Body & & $\mathrm{J} \& \mathrm{~J}$ \\
\hline 23 & Nivea Protege e Hidrata FPS30 ${ }^{\circledR}$ & Body & & Beiersdorf AG \\
\hline 24 & Roc Minesol Oil Control FPS70 ${ }^{\circledR}$ & Face & & $\mathrm{J} \& \mathrm{~J}$ \\
\hline 25 & Roc Minesol Oil Control FPS30 $0^{\circledR}$ & Face & & $\mathrm{J} \& \mathrm{~J}$ \\
\hline 26 & Shiseido Ultimate Sun Protection FPS50 ${ }^{\circledR}$ & Body & & Shiseido \\
\hline 27 & Sundown FPS30 $0^{\circledR}$ & Body & & $\mathrm{J} \& \mathrm{~J}$ \\
\hline 28 & Sundown Todo Dia FPS30 ${ }^{\circledR}$ & Body & & $\mathrm{J} \& \mathrm{~J}$ \\
\hline 29 & Vichy Captal Soleil FPS50® & Face & & L'Oreal \\
\hline 30 & Aneesa Perfect UV FPS50+ PA++++ ${ }^{\circledR}$ & Face & \multirow{10}{*}{$\begin{array}{c}\text { North } \\
\text { America }\end{array}$} & Shiseido \\
\hline 31 & Banana Boat Sport Performance Lotion ${ }^{\circledR}$ Sunscreen Broad Spectrum FPS50+ ${ }^{\circledR}$ & Body & & Energizer \\
\hline 32 & Elta MD Skincare UV Shield FPS45 ${ }^{\circledR}$ & Face & & $\begin{array}{l}\text { Colgate- } \\
\text { Palmolive }\end{array}$ \\
\hline 33 & La Roche Posay Anthelios Cooling Water-Lotion FPS60 ${ }^{\circledR}$ & Face & & L'Oreal \\
\hline 34 & Neutrogena Beach Defense Sunscreen Lotion FPS70 ${ }^{\circledR}$ & Body & & $\mathrm{J} \& \mathrm{~J}$ \\
\hline 35 & Neutrogena Clear face Liquid Lotion FPS55 ${ }^{\circledR}$ & Face & & $\mathrm{J} \& \mathrm{~J}$ \\
\hline 36 & Neutrogena Hydro Boost Water Gel Lotion ${ }^{\circledR}$ FPS50 $^{\circledR}$ & Face & & $\mathrm{J} \& \mathrm{~J}$ \\
\hline 37 & Neutrogena Ultra Sheer Dry-Touch FPS100+ ${ }^{\circledR}$ & Face & & $\mathrm{J} \& \mathrm{~J}$ \\
\hline 38 & Shiseido Perfect UV Protector FPS50 $+{ }^{\circledR}$ PA++++ WetForce ${ }^{\circledR}$ & Body & & Shiseido \\
\hline 39 & Sun Bum Sunscreen Lotion Advanced Broad Spectrum FPS70 $0^{\circledR}$ & Body & & SC Johnson \\
\hline
\end{tabular}

variables employed, that is, on the rheological data used (G', tixotropy and yield stress). The program employed to train and test the neural networks was the Neural Networks Toolbox $^{\circledR}$, commercially available for use with Matlab.
In this toolbox, the algorithms were developed for training in lots. The percentage of consumer acceptance estimated in the simulation was compared to the experimental results obtained in the sensorial analysis. 
Table 2. Codes used to identify the samples.

\begin{tabular}{cc}
\hline Code & Sample collection region \\
\hline 1A, 2A, 3A, 4A, 5A, 6A, 7A, 8A & Asia \\
\hline 1E, 2E, 3E, 4E, 5E, 6E, 7E, 8E, 9E & Europe \\
\hline 1NA, 2NA, 3NA, 4NA, 5NA, 6NA, 7NA, 8NA, 9NA, 10NA & North America \\
\hline 1SA, 2SA, 3SA, 4SA, 5SA, 6SA, 7SA, 8SA, 9SA, 10SA, 11SA, 12SA & South America \\
\hline
\end{tabular}

\section{Results and Discussion}

\subsection{Rheological characterization}

The rheological parameters identified in the literature ${ }^{5,6,24-28}$ as relevant to prediction methods are the G' values in different frequency sweeps (in this study values of $0.01,10$ and $50 \mathrm{rad} / \mathrm{s}$ were employed), the yield stress and thixotropy value, obtained from the flow curves. In relation to the analysis with frequency sweep, Brummer ${ }^{24}$ discusses the correlation of rheological data obtained for primary sensorial aspects, resulting from sensorial analysis conducted with consumers, where a positive value is associated with a high yield stress. In relation to the secondary sensorial aspects, when the product has been almost completely spread on the skin it should present a decrease in viscosity (i.e., in consistency), facilitating its application. At the same time, the product should support higher shear rates and present thixotropy.

Figure 1 shows rheological curves for the shear stress $(\tau)$ as a function of the shear rate $(\gamma)$, for the samples 3SA and 4SA, both from South America. The curves show that these emulsions present non-Newtonian behavior of the pseudoplastic type with thixotropy, in agreement with the literature ${ }^{24-28}$. In general, thixotropic behavior is observed in weakly flocculated systems, since, when the shear is applied the rupture or breakage of the smaller organized structure is observed, and when the shear is removed, the organized system regains its integrity (hysteresis). Strongly flocculated emulsions usually present a low degree of (or zero) thixotropy, that is, they are characterized as pseudoplastics ${ }^{26-28}$.

For some very fluid products, very low thixotropy values are observed or the result may be 'not determined', as in the case of products $3 \mathrm{NA}$ and $8 \mathrm{NA}$ (Table 3 ). In general, the Asian products present lower thixotropy values since they have lower viscosity due to the addition of powder to their compositions in order to meet regional requirements related to the sensorial perception desired by consumers. European products present reduced thixotropy values because they are less viscous. Products from South America and the North America present, in general, intermediate thixotropy values.

Figure 2 shows typical flow curves (stress vs. strain) for a sample from each global region analyzed ${ }^{24-28}$. Based on these curves, the yield stress can be obtained. This value is taken from the point at which the curve shows a change in behavior (indicated by the blue arrow in the graph) and is characterized by a loss of the elastic component $\left(G^{\prime}\right)$ of the material, that is, the rupture of the emulsion structure. This value has an important relation with the kinetic stability and sensorial aspects of cosmetic emulsions ${ }^{6}$.

Table 3 shows the yield stress (Pa) for all samples analyzed in this study, and the differences observed may be due to variations in the manufacturing processes in different global regions and

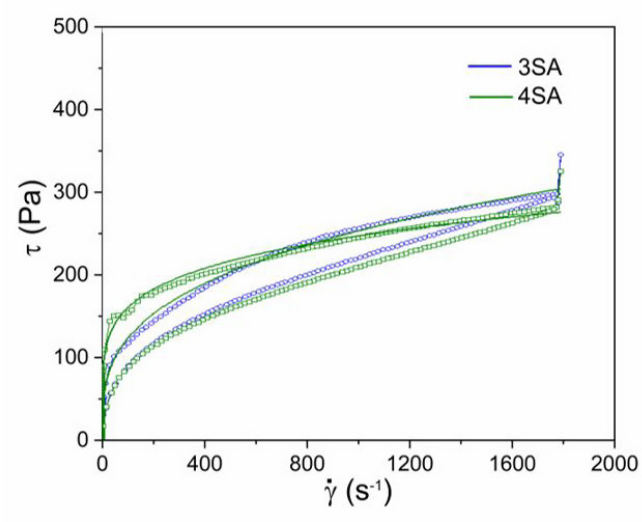

Figure 1. Rheological curves for shear stress $(\tau)$ versus shear rate $(\gamma)$.

in the formulation and technology employed, even when the manufacturer is the same. The yield stress, as in the case of thixotropy, is influenced by the viscosity of the emulsion and also its behavior when submitted to shear stress ${ }^{24-28}$.

Figure 3 shows typical examples of the frequency sweep curves for a product from each region. Tests in the oscillatory regime showed that the G' value (red curve) is higher than the G" value (blue curve), which characterizes solid viscoelastic behavior. In this case, the emulsion shows the texture of a thick cream. When G" > G', the emulsions show liquid viscoelastic behavior, with the texture of a light $\mathrm{cream}^{5}$.

The literature shows that the higher G' value with an increase in the frequency provides the product with an agreeable sensation, with greater adherence to the skin. This occurs when the dynamic viscosity ( $\eta^{*}$, orange curve) decreases linearly. This behavior is commonly observed for products with a sun protection factor, enhancing the sensation of skin protection ${ }^{2,11,24}$. A larger distance between $G$ ' and $G$ " indicates greater kinetic stability of the product, that is, a longer shelf life ${ }^{24}$.

Table 3 shows the results for the parameter G', obtained at different frequencies $(0.01,10$ and $50 \mathrm{rad} / \mathrm{s})$, the yield stress and the thixotropy for the cosmetic emulsions studied. The collection of these data was based on curves similar to those presented in Figures 1-3. The comparative analysis of the results in this table does not reveal behavioral tendencies for the samples of the same region or different regions. This is due to the processing techniques applied in different regions and different product formulations, even for the same manufacturer. These rheological data were employed in the simulations performed with neural networks.

\subsection{Sensorial analysis}

The samples were comprised of different cosmetic emulsions designed for different purposes and consumers evaluate products for the face and body employing different 
Table 3. Rheological parameters (G', yield stress and thixotropy) of the emulsions.

\begin{tabular}{|c|c|c|c|c|c|c|}
\hline \multirow[b]{2}{*}{ Region } & \multirow[b]{2}{*}{ Sample } & \multicolumn{3}{|c|}{ Frequency sweep } & \multicolumn{2}{|c|}{ Flow curves } \\
\hline & & $\begin{array}{c}\mathrm{G}^{\prime}(\mathrm{Pa}) \\
0.01 \mathrm{rad} / \mathrm{s}\end{array}$ & $\begin{array}{l}\mathrm{G}^{\prime}(\mathrm{Pa}) \\
10 \mathrm{rad} / \mathrm{s}\end{array}$ & $\begin{array}{c}\mathrm{G}^{\prime}(\mathrm{Pa}) \\
50 \mathrm{rad} / \mathrm{s}\end{array}$ & Yield stress $(\mathrm{Pa})$ & $\begin{array}{c}\text { Thixotropy } \\
(\mathrm{MPa} / \mathrm{s})\end{array}$ \\
\hline \multirow{8}{*}{ Asia } & $1 \mathrm{~A}$ & 10.7 & 23.5 & 31.8 & 187.0 & 134.4 \\
\hline & $2 \mathrm{~A}$ & 64.7 & 98.8 & 154.5 & 180.8 & 149.5 \\
\hline & $3 \mathrm{~A}$ & 305.1 & 459.9 & 540.7 & 448.8 & 726.2 \\
\hline & $4 \mathrm{~A}$ & 31.8 & 48.0 & 58.0 & 112.9 & 108.8 \\
\hline & $5 \mathrm{~A}$ & 32.3 & 43.5 & 44.6 & 109.1 & 103.9 \\
\hline & $6 \mathrm{~A}$ & 67.0 & 114.8 & 136.5 & 331.5 & 350.5 \\
\hline & $7 \mathrm{~A}$ & 1496.5 & 1887.0 & 2093.0 & 147.8 & 771.0 \\
\hline & $8 \mathrm{~A}$ & 721.7 & 2157.1 & 2726.5 & 200.1 & 286.8 \\
\hline \multirow{9}{*}{ Europe } & $1 \mathrm{E}$ & 1045.6 & 2211.9 & 2777.1 & 90.2 & 89.8 \\
\hline & $2 \mathrm{E}$ & 68.8 & 314.4 & 394.2 & 21.0 & 5.8 \\
\hline & $3 \mathrm{E}$ & 100.9 & 252.3 & 324.1 & 83.2 & 32.2 \\
\hline & $4 \mathrm{E}$ & 20.4 & 37.7 & 50.7 & 6.8 & 9.7 \\
\hline & $5 \mathrm{E}$ & 117.1 & 290.7 & 344.9 & 53.7 & 0.2 \\
\hline & $6 \mathrm{E}$ & 458.9 & 691.4 & 767.9 & 100.6 & 2.6 \\
\hline & $7 \mathrm{E}$ & 39.6 & 69.7 & 84.3 & 23.9 & 5.6 \\
\hline & $8 \mathrm{E}$ & 9.1 & 137.4 & 174.5 & 3.4 & 7.8 \\
\hline & $9 \mathrm{E}$ & 47.5 & 254.0 & 312.6 & 14.0 & 50 \\
\hline \multirow{12}{*}{ South America } & $1 \mathrm{SA}$ & 36.7 & 75.6 & 91.9 & 18.2 & 5.1 \\
\hline & $2 \mathrm{SA}$ & 68.5 & 286.0 & 355.1 & 30.1 & 20.1 \\
\hline & $3 \mathrm{SA}$ & 224.0 & 413.4 & 475.7 & 73.7 & 40.3 \\
\hline & $4 \mathrm{SA}$ & 277.8 & 878.0 & 1060.8 & 116.2 & 39.0 \\
\hline & $5 \mathrm{SA}$ & 523.7 & 1300.3 & 1570.4 & 126.4 & 65.9 \\
\hline & $6 \mathrm{SA}$ & 9.5 & 24.0 & 32.9 & 6.1 & 14.7 \\
\hline & $7 \mathrm{SA}$ & 198.5 & 632.9 & 792.3 & 56.5 & 47.5 \\
\hline & $8 \mathrm{SA}$ & 234.6 & 687.9 & 885.2 & 91.3 & 43.4 \\
\hline & 9SA & 6.6 & 22.9 & 32.2 & 2.7 & 3.3 \\
\hline & 10SA & 107.4 & 296.8 & 370.9 & 67.5 & 40.3 \\
\hline & 11SA & 624.9 & 1844.2 & 2656.2 & 117.9 & 43.8 \\
\hline & 12SA & 215.3 & 3459.6 & 4318.1 & 56.6 & 10.8 \\
\hline \multirow{10}{*}{$\begin{array}{l}\text { North } \\
\text { America }\end{array}$} & 1NA & 308.3 & 653.4 & 856.2 & 75.8 & 14.9 \\
\hline & $2 \mathrm{NA}$ & 562.8 & 1621.3 & 1969.3 & 100.9 & 85.2 \\
\hline & $3 \mathrm{NA}$ & 41.6 & 85.3 & 106.7 & 8.3 & nd \\
\hline & $4 \mathrm{NA}$ & 127.4 & 527.7 & 654.5 & 39.6 & 30.4 \\
\hline & $5 \mathrm{NA}$ & 561.0 & 1497.7 & 2046.4 & 99.1 & 49.3 \\
\hline & $6 \mathrm{NA}$ & 23.0 & 108.8 & 189.6 & 24.1 & 21.6 \\
\hline & 7NA & 150.0 & 283.2 & 338.7 & 26.6 & 4.9 \\
\hline & $8 \mathrm{NA}$ & 32.7 & 128.7 & 235.5 & 42.4 & nd \\
\hline & 9NA & 295.4 & 540.6 & 744.4 & 32.2 & 23.0 \\
\hline & $10 \mathrm{NA}$ & 6.2 & 22.4 & 29.9 & 2.7 & 39 \\
\hline
\end{tabular}

nd - not determined.

criteria. Therefore, in this study, these two types of products were analyzed separately, aiming to reach higher precision in the prediction results. Facial products have a smaller oily portion and lower viscosity, enhancing the pleasant sensation during the act of spreading. Body products, in general, have higher concentrations of emollients and slightly higher viscosity in order to facilitate good spreading in larger areas ${ }^{14,36}$.

It should be noted that differences in perception have been observed for different regions of the same continent, as reported in the literature ${ }^{14,36}$. Female Brazilians, for instance, have more oily skin due to genetic and climatic factors while Europeans have drier and more sensitive skin for the same reasons. In Asia, consumers prefer products with lower viscosity and with particular spreading properties, requiring manufacturers to add more silicone in the formulations. In the North America, the main focus is on the visual aspect of products on shelves and therefore the packaging plays a major role in the decision to buy ${ }^{36}$. Considering these aspects, the model to be researched in this study takes into account the parameter 'region', which is defined as the target for the development of the formula under study.

Table 4 shows the consumer preference regarding the attribute 'general impression' for products in Asia, which were organized to form part of the prediction model. The results obtained for 'general impression' were analyzed using an evaluation method employed in market research (TTB), 

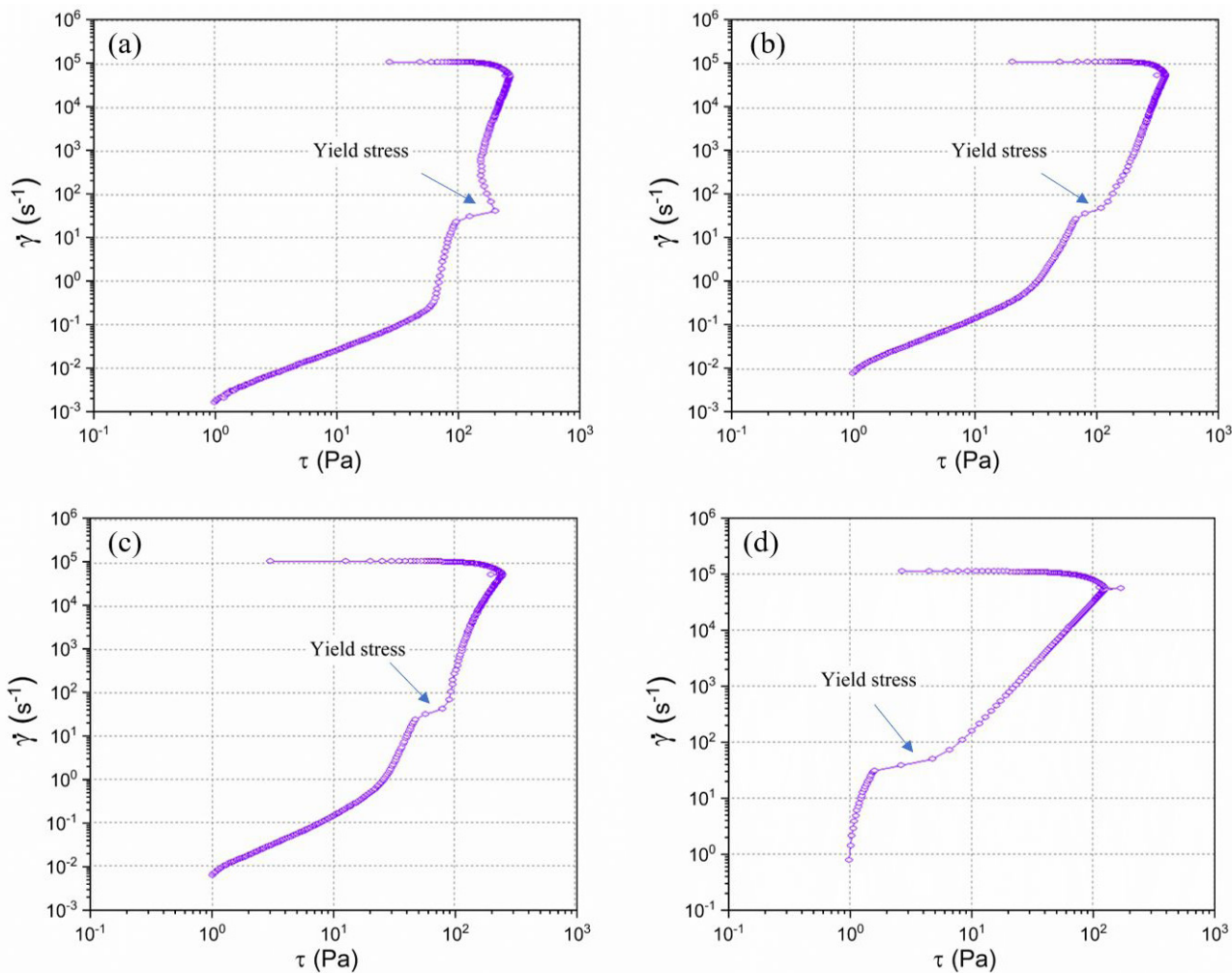

Figure 2. Curves showing the yield stress (shear rate versus shear stress) for the samples (a) 2A, (b) 3E, (c) 7SA and (d) 10NA.
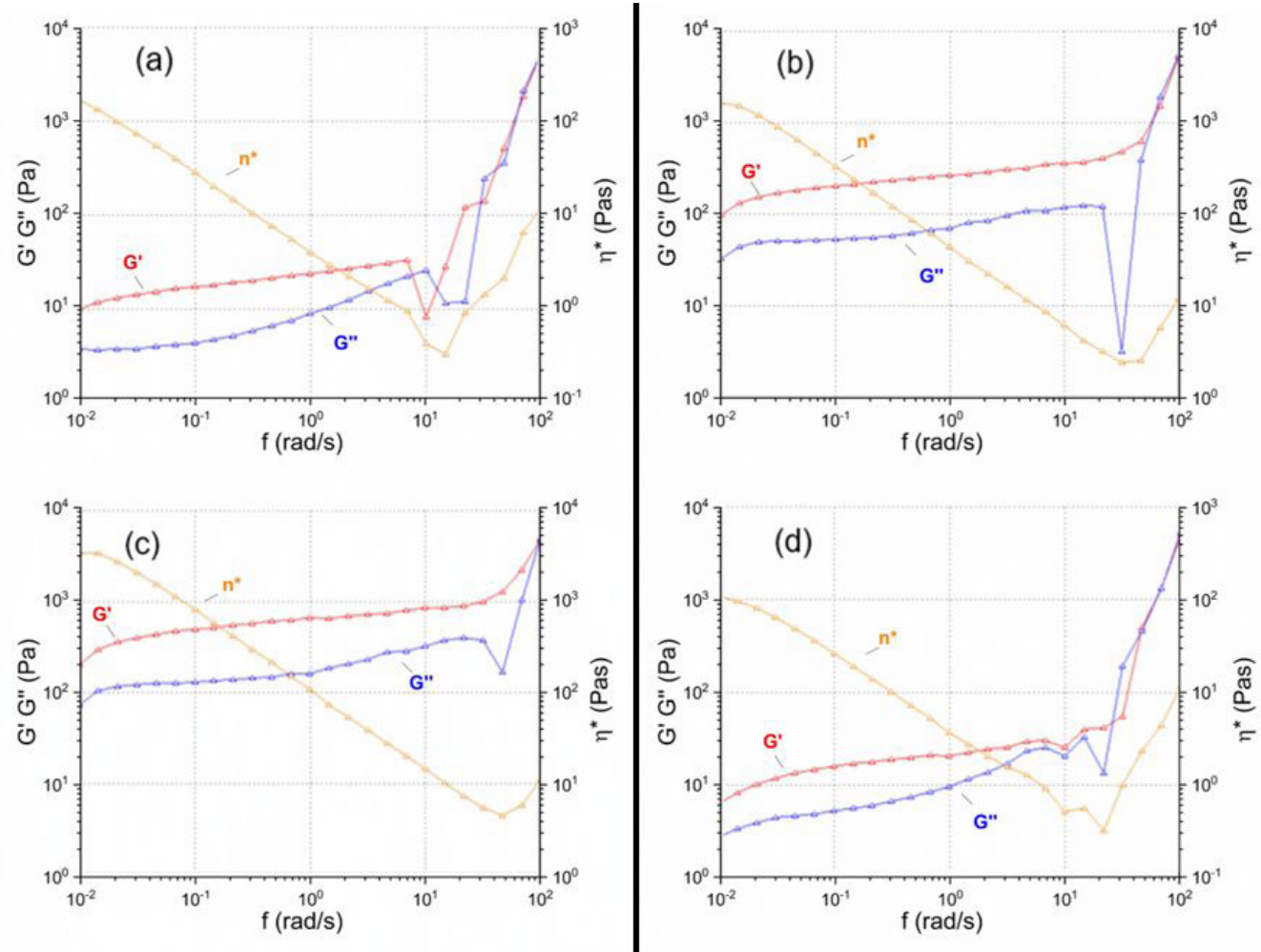

Figure 3. Frequency sweep curves (G' versus frequency) of samples (a) 2A, (b) 3E, (c) 7SA and (d) 10NA. G' in red, G' in blue, $\eta^{*}$ in orange. 
Table 4. Sensorial analysis of attribute 'general impression' for products in Asia.

\begin{tabular}{|c|c|c|c|c|c|c|}
\hline \multirow{2}{*}{ Region } & \multirow{2}{*}{ Sample } & \multicolumn{5}{|c|}{ General impression (TTB - \%) } \\
\hline & & 1 & 2 & 3 & 4 & 5 \\
\hline \multirow{8}{*}{ Asia } & $1 \mathrm{~A}$ & 0 & 5 & 27 & 51 & 17 \\
\hline & $2 \mathrm{~A}$ & 1 & 12 & 23 & 53 & 11 \\
\hline & $3 \mathrm{~A}$ & 4 & 12 & 36 & 37 & 11 \\
\hline & $4 \mathrm{~A}$ & 0 & 19 & 17 & 48 & 16 \\
\hline & $5 \mathrm{~A}$ & 0 & 8 & 28 & 47 & 17 \\
\hline & $6 \mathrm{~A}$ & 1 & 15 & 20 & 51 & 13 \\
\hline & $7 \mathrm{~A}$ & 0 & 7 & 33 & 44 & 16 \\
\hline & $8 \mathrm{~A}$ & 0 & 12 & 33 & 44 & 11 \\
\hline
\end{tabular}

Table 5. Sensorial analysis of the attribute 'fragrance intensity' for products in Asia.

\begin{tabular}{|c|c|c|c|c|c|c|c|}
\hline \multirow{2}{*}{ Region } & \multirow{2}{*}{ Sample } & \multicolumn{6}{|c|}{ Fragrance Intensity (JAR - \%) } \\
\hline & & -- & - & JAR & + & & ++ \\
\hline \multirow{8}{*}{ Asia } & $1 \mathrm{~A}$ & & & 76 & & 20 & \\
\hline & $2 \mathrm{~A}$ & & & 67 & & 25 & \\
\hline & $3 \mathrm{~A}$ & & & 59 & & 39 & \\
\hline & $4 \mathrm{~A}$ & & & 79 & & 16 & \\
\hline & $5 \mathrm{~A}$ & & & 71 & & 25 & \\
\hline & $6 \mathrm{~A}$ & & & 67 & & 24 & \\
\hline & $7 \mathrm{~A}$ & & & 69 & & 21 & \\
\hline & $8 \mathrm{~A}$ & & & 55 & & 41 & \\
\hline
\end{tabular}

the aim of which is to report the results to the questions on a category scale, where two main responses are combined, as described by the Society of Sensory Professionals ${ }^{37}$. According to this society, the acceptance of a product is generally established as a success for values of $80 \%$ or above. This means that the addition of the percentages for the responses to questions 4 and 5 must be $\geq 80 \%$. Table 4 shows that the product most accepted in Asia is 2 A with a TTB result of $69 \%$.

Table 5 shows data referring to the preference of consumers for the attribute 'fragrance intensity' for products in Asia, illustrating how the data were organized in order to be included in the prediction model. For this attribute, the JAR evaluation method used in market research was employed. This scale measures the acceptability of the level of a specific attribute and is used in order to determine the optimum levels of the attribute for a product. In tests with cosmetic creams, consumers are frequently asked if a sensorial characteristic of a product, for instance the consistency, is too high, too low or almost right. These 'diagnoses of attributes' are included in order to help researchers to understand why consumers like or do not like a product and also to guide the development efforts with the objective of increasing the level of consumer acceptance of the product.

Figure 4 shows histograms related to sensorial attributes employed in the prediction model under study, where it can be observed how the results for consumer perception are presented for this sample. The histograms in Figure 4a were obtained through the JAR method and those in Figure $4 \mathrm{~b}$ through the TTB method for each group of attributes analyzed.

\subsection{Modeling of data using ANN}

During the organization of data obtained from the sensorial analysis to be employed in the comparison with the results of the simulations, a low frequency of consumer responses at the extreme points of the scale (i.e., values 1 and 5) was noted. Thus, the results were regrouped into scores of 2 and 4, respectively, and the original scale was reorganized into three categories: the new scale 1, which grouped the original scores 1 and 2; the new scale 2, which was previously score 3 ; and the new scale 3 , which grouped scores 4 and 5 . This grouping of consumer responses into three categories was carried out to obtain a higher precision in the comparison of the simulation values with the experimental results from sensorial analysis performed with consumers. The rearrangement of the responses in the sensorial analysis was based on Equations 1 and 2, as described in the literature $\mathrm{e}^{30,32,33}$.

$$
\begin{aligned}
& \log \left(\frac{p_{1}}{1-p_{1}}\right)=\operatorname{Bias}\left(y_{1}\right)+w_{11} H_{11}+w_{12} H_{12}+w_{13} H_{13} \\
& \log \left(\frac{p_{1}+p_{3}}{1-p_{1}-p_{3}}\right)=\operatorname{Bias}\left(y_{3}\right)+w_{11} H_{11}+w_{12} H_{12}+w_{13} H_{13}
\end{aligned}
$$

where: $p_{1}$ and $p_{3}$ are the probability of occurrence of categories 1 and 3 , respectively, $\mathrm{y}_{1}$ and $\mathrm{y}_{3}$ are the values which will generate the prediction, $\mathrm{w}_{\mathrm{ij}}$ refers to the values which comprise the fundamental basis of the model and $\mathrm{H}_{\mathrm{ij}}$ represents the prediction result. 


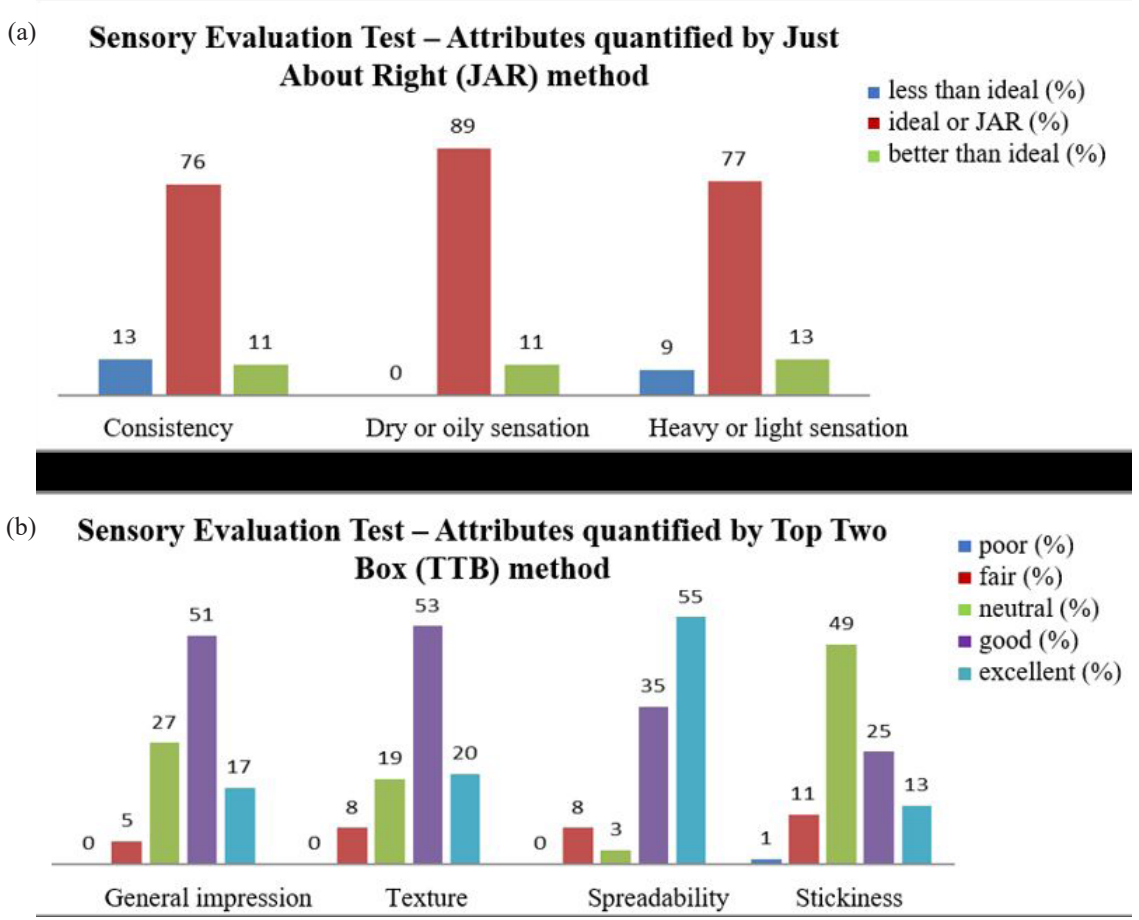

Figure 4. Histograms of attributes quantified by JAR (a) and TTB (b) methods.

Equation 3 represents the equation of the predictive model, according to Haykin ${ }^{31}$.

$H_{i j}=\tan h\left(\operatorname{Bias}\left(H_{i j}\right)+w_{i 1} X_{1}+w_{i 2} X_{2}+\ldots+w_{i p} X_{p}\right), i=1, \ldots, q$

where: $X_{1}, \ldots, X_{p}$ are the probability values generated with the limits of the original data of the study with which the model was built.

Based on the organization of data obtained from the sensorial analysis, the models were constructed using neural networks considering the $\mathrm{G}^{\prime}(\mathrm{Pa})$ values obtained at frequencies of $0.01,10$ and $50 \mathrm{rad} / \mathrm{s}$, the yield stress defined from the flow curve and the thixotropy. The simulations were carried out independently for each attribute, considering general impression, consistency, spreadability, stickiness, product sensation on dry and oily skin, and heavy or light texture.

On building the model with neural networks, the rheological data were partitioned into two exclusive subsets: training samples and validation samples. The training samples consisted in $70 \%$ of the determinations, randomly selected from the original data set. The original data refers to the results of rheological analysis generated in the study, which were divided into training and validation samples, to be employed in the model. Based on the results obtained in the simulations with the use of the model, the proximity of the simulated results to the responses obtained experimentally in the sensorial analysis was evaluated.

After the fitting of the models using the neural networks in the training stage, the samples selected for the validation stage were tested and the results obtained from the simulation were compared with consumer responses obtained in the sensorial analysis. As a result of this comparison, the simplest and most precise model, that is, the one which best fitted the experimental results, was selected for the rheological data set.

Table 6 shows the precision percentage for each attribute simulated based on the validation samples. It can be observed that the highest precision was obtained for the attributes general impression (61-78\%) and spreadability (69-84\%). These results validate the use of rheology as a suitable tool in the characterization of the physical aspects of cosmetic emulsions and the inclusion of primary and secondary sensorial aspects in the prediction of sensorial characteristics perceived by consumers. Spreadability showed notable results, and this physically represents the type of useful information that can be achieved through an understanding of rheological analysis.

Table 7 shows the attributes studied that could be predicted with precision higher than $60 \%$, by global region and based on rheological characteristics. For instance, in the case of products for the body, considering South America, 4 attributes could be predicted (general impression, consistency, spreadability and heavy-light skin sensation) of the 5 attributes evaluated using the predictive method.

In general, the precision estimates for prediction models are based on the space generated by the values of the variables employed in the training stage. For predictions resulting from data outside of this space error estimates cannot be obtained and therefore it is recommended that these models are employed only with data inserted in the space under study. Table 8 shows the ranges (minimum and maximum values) of the data obtained from the rheological analysis for each variable used in the simulations. These values delimit the 
Table 6. Percentage precision for the correlation between consumer perception and rheological data obtained employing the prediction model based on neural networks.

\begin{tabular}{|c|c|c|c|}
\hline Attribute & Region & Type & Precision $(\%)$ \\
\hline \multirow{7}{*}{ General impression } & \multirow{2}{*}{ South America } & Body & 77 \\
\hline & & Face & 69 \\
\hline & Europe & Body & 71 \\
\hline & \multirow{2}{*}{ North America } & Body & 78 \\
\hline & & Face & 65 \\
\hline & \multirow{2}{*}{ Asia } & Body & 61 \\
\hline & & Face & 61 \\
\hline \multirow{9}{*}{ Product consistency (fine/thick) } & \multirow{2}{*}{ South America } & Body & 68 \\
\hline & & Face & 69 \\
\hline & \multirow{2}{*}{ South America } & Body & 68 \\
\hline & & Face & 69 \\
\hline & Europe & Body & $57 *$ \\
\hline & \multirow{2}{*}{ North America } & Body & 69 \\
\hline & & Face & $57 *$ \\
\hline & \multirow{2}{*}{ Asia } & Body & $59 *$ \\
\hline & & Face & 69 \\
\hline \multirow{7}{*}{ Spreadability (easy/difficult) } & \multirow{2}{*}{ South America } & Body & 69 \\
\hline & & Face & 72 \\
\hline & Europe & Body & 84 \\
\hline & \multirow{2}{*}{ North America } & Body & 75 \\
\hline & & Face & 71 \\
\hline & \multirow{2}{*}{ Asia } & Body & 70 \\
\hline & & Face & 82 \\
\hline \multirow{7}{*}{$\begin{array}{l}\text { Sensation on skin } \\
\text { (oily/dry) }\end{array}$} & \multirow{2}{*}{ South America } & Body & $49 *$ \\
\hline & & Face & 66 \\
\hline & Europe & Body & $55^{*}$ \\
\hline & \multirow{2}{*}{ North America } & Body & $57 *$ \\
\hline & & Face & 61 \\
\hline & \multirow{2}{*}{ Asia } & Body & $59 *$ \\
\hline & & Face & 73 \\
\hline \multirow{7}{*}{$\begin{array}{l}\text { Sensation on skin } \\
\text { (heavy/light) }\end{array}$} & \multirow{2}{*}{ South America } & Body & 60 \\
\hline & & Face & $54 *$ \\
\hline & Europe & Body & 64 \\
\hline & \multirow{2}{*}{ North America } & Body & 64 \\
\hline & & Face & 61 \\
\hline & \multirow{2}{*}{ Asia } & Body & $53 *$ \\
\hline & & Face & 70 \\
\hline
\end{tabular}

*Prediction below expected $(<60 \%)$.

Table 7. Number of attributes (out of 5 evaluated) for which sensorial analysis results were predicted by the ANN model with precision higher than $60 \%$.

\begin{tabular}{|c|c|c|c|c|c|c|}
\hline \multicolumn{2}{|c|}{ South America } & \multirow{2}{*}{$\begin{array}{c}\text { Europe } \\
\text { Body } \\
\end{array}$} & \multicolumn{2}{|c|}{ North America } & \multicolumn{2}{|c|}{ Asia } \\
\hline Body & Face & & Body & Face & Body & Face \\
\hline $4 / 5$ & $4 / 5$ & $3 / 5$ & $4 / 5$ & $4 / 5$ & $2 / 5$ & $5 / 5$ \\
\hline
\end{tabular}

Table 8. Range of values for rheological properties which define the space for the prediction of sensorial aspects of cosmetic emulsions.

\begin{tabular}{|c|c|c|c|c|c|c|c|c|c|c|c|c|}
\hline \multirow{2}{*}{ Variable $(\mathrm{Pa})$} & \multicolumn{3}{|c|}{ South America } & \multicolumn{3}{|c|}{ North America } & \multicolumn{3}{|c|}{ Europe } & \multicolumn{3}{|c|}{ Asia } \\
\hline & $\mathrm{N}$ & Min & Max & $\mathrm{N}$ & Min & Max & $\mathrm{N}$ & Min & Max & $\mathrm{N}$ & Min & Max \\
\hline $\mathrm{G}^{\prime}-0.01 \mathrm{rad} / \mathrm{s}$ & 12 & 6.6 & 624.9 & 10 & 6.6 & 561.0 & 9 & 9.1 & 1045.6 & 8 & 10.7 & 1496.5 \\
\hline $\mathrm{G}^{\prime}-10 \mathrm{rad} / \mathrm{s}$ & 12 & 22.9 & 3459.6 & 10 & 22.9 & 1622.6 & 9 & 37.7 & 2211.9 & 8 & 23.5 & 2157.1 \\
\hline G' - $50 \mathrm{rad} / \mathrm{s}$ & 12 & 32.2 & 4318.1 & 10 & 32.2 & 1971.0 & 9 & 50.7 & 2777.1 & 8 & 31.8 & 2726.5 \\
\hline Yield stress & 12 & 2.7 & 126.4 & 10 & 2.7 & 100.9 & 9 & 3.4 & 100.6 & 8 & 109.1 & 448.8 \\
\hline
\end{tabular}


space for new simulations to be conducted with acceptable precision, aimed at the production of new emulsions.

\section{Conclusions}

This study was carried out in a challenging experimental context since the emulsion preparation technologies and the general impression of consumers can vary in different regions around the world (Asia, Europe, North America, South America). The results obtained demonstrate that statistical modeling with the use of neural networks and rheological data (G', yield stress and thixotropy), for 39 samples of cosmetic emulsions, was successful. The model was able to predict, with good precision (60-84\%), consumer perception in relation to the use of cosmetic emulsions. In the rheological analysis tests were carried out in the oscillatory and stationary regimes. The rheological results showed that each sample has distinct characteristics and trends within or between regions were not observed due to the complexity of each emulsion formula and the processing technology employed by different manufacturers in the regions analyzed.

The results of this study support the use of the model studied by one of the main manufacturers of cosmetics globally, in research and development in the area of skincare products, aimed at the reduction of physical and financial resources and time. These benefits are due to the model offering an important tool in decision making in relation to the technological path to be adopted in new developments or in the adjustment of existing formulations. The statistical model developed in this study continues to be updated in order to improve its fit with the experimental data and increase its reliability.

\section{Acknowledgments}

The authors acknowledge the financial support received from $\mathrm{CNPq}$ (Conselho Nacional de Desenvolvimento Cientifico e Tecnológico) (305123/2018-1), CAPES (Coordenação de Aperfeiçoamento de Pessoal de Nível Superior) (001), and Johnson \& Johnson Co. in São José dos Campos/SP, Brazil.

\section{References}

1. Huma S, Khan HMS, Sohail M, Akhtar N, Rasool F, Majeed $\mathrm{F}$, et al. Development, in-vitro characterization and assessment of cosmetic potential of Beta vulgaris extract emulsion. J Herb Med. 2020;23:100372.

2. Hong JS, Bergfreund J, Fischer P. Complex emulsion stabilization behavior of clay particles and surfactants based on an interfacial rheological study. Colloids Surf A Physicochem Eng Asp. 2020;602:125121.

3. Calvo F, Gómez JM, Sandoval LR, Alvarez O. Integrated design of emulsified cosmetic products: a review. Chem Eng Res Des. 2020;161:279-303.

4. Daltin D. Tensoativos - química, propriedade e aplicações. São Paulo: Blucher; 2011.

5. Kaganyuk M, Mohraz A. Role of particles in the rheology of solid-stabilized high internal phase emulsions. J Colloid Interface Sci. 2019;540:197-206.

6. Kamkar M, Bazazi P, Kannan A, Suja VC, Hejazi SH, Fuller GG, et al. Polymeric-nanofluids stabilized emulsions: interfacial versus bulk rheology. J Colloid Interface Sci. 2020;576:252-63.

7. Dehoff R. Thermodynamics in materials science. Florida: CRC Press; 2006.
8. Rosen MJ, Kunjappu JT. Surfactants and interfacial phenomena. New York: Wiley; 2012.

9. Venkataramani D, Tsulaia A, Amin S. Fundamentals and applications of particle stabilized emulsions in cosmetic formulations. Adv Colloid Interface Sci. 2020;283:102234.

10. Gilbert L, Picard C, Savary G, Grisel M. Rheological and textural characterization of cosmetic emulsions containing natural and synthetic polymers: relationships between both data. Colloids Surf A Physicochem Eng Asp. 2013;421:150-63.

11. Savary G, Grisel M, Picard C. Impact of emollients on the spreading properties of cosmetic products: a combined sensory and instrumental characterization. Colloids Surf B Biointerfaces. 2013;102:371-8

12. Institute of Food Technologists. [homepage on the Internet]. Chicago; 2019 [cited 2019 Nov 10]. Available from: https:// www.ift.org

13. Retondo CG, Faria P. Química das sensações. Campinas: Átomo; 2014.

14. Harris MINC. Pele - estrutura, propriedades e envelhecimento. São Paulo: Senac; 2003.

15. Ribeiro C. Cosmetologia aplicada a dermoestetica. São Paulo: Pharmabook; 2010.

16. Ding S, Bhushan B. Tactile perception of skin and skin cream by friction induced vibrations. J Colloid Interface Sci. 2016;481:131-43.

17. Winter R. A consumer's dictionary of cosmetic ingredients. New York: Three Rivers Press; 2009.

18. Gámbaro A, Roascio A, Boinbaser L, Pérez S, Parente E. Application of two projective techniques in the study of consumer perception of antiperspirant/deodorants. J Sens Stud. 2018;34(1):e12478.

19. David OA, David DO, Mogoase C, Popescu LC, Giosan C, Pellegrino A. Psychological effects and brain correlates of a rosebased scented cosmetic cream. J Sens Stud. 2019;34(6):e12536.

20. Parente E, Ares G. How do appearance and fragrance influence expectations and conceptual associations of cosmetic products? An exploratory case study with liquid hand soap. J Sens Stud. 2020;36(2):e12637.

21. Laba D. Rheological properties of cosmetics and toiletries. Florida: CRC Press; 1993.

22. Lukic M, Jaksic I, Krstonosic V, Dokic L, Savic S. Effect of small change in oil phase composition on rheological and textural properties of W/O emulsion. J Texture Stud. 2012;44:34-44.

23. Lukic M, Jaksic I, Krstonosic V, Cekic N, Savic S. A combined approach in characterization of an effective w/o hand cream: the influence of emollient on textural, sensorial and in vivo skin performance. Int J Cosmet Sci. 2012;34:140-9.

24. Brummer R. Rheology essentials of cosmetic and food emulsions. Berlin: Springer; 2005.

25. Ozdogan G, Lin X, Sun DW. Rapid and noninvasive sensory analyses of food products by hyperspectral imaging: recent application developments. Trends Food Sci Technol. 2021;111:15165.

26. Tadros T. Application of rheology for assessment and prediction of the long-term physical stability of emulsions. Adv Colloid Interface Sci. 2004;108-109:227-58.

27. Tadros TF. Rheology of dispersions: principles and applications. Weinheim: Wiley-VCH; 2011.

28. Tadros TF. Colloids in cosmetics and personal care. Weinheim: Wiley-VCH; 2008.

29. Castro AG, Covas JA, Diogo AC. Reologia e suas aplicações industriais. São Paulo: Instituto Piaget; 2001.

30. Hayes AF, Preacher KJ. Statistical mediation analysis with a multicategorical independent variable. Br J Math Stat Psychol. 2014;67(3):451-70.

31. Haykin S. Neural networks, a comprehensive foundation. Londres: Pearson; 1998. 
32. Pimentel WSO. Aplicação de redes neurais artificiais e quimiometria na modelagem do processo de craqueamento catalítico fluido [tese]. Campinas: Universidade Estadual de Campinas; 2005.

33. Resende JV. Redes neurais artificiais e modelos de regressão na predição de propriedades reológicas de méis brasileiros [tese]. Lavras: Universidade Federal de Lavras; 2016.

34. Dhagat S, Jujjavarapu SE. Simulated annealing and artificial neural network as optimization tools to enhance yields of bioemulsifier and exopolysaccharides by thermophilic Brevibacillus borstelensis. J Environ Chem Eng. 2021;9:105499.
35. Bezerra FLA. Desenvolvimento de um controle preditivo baseado em modelo de rede neural artificial em um processo de fermentação contínua de segunda geração [dissertação]. Campinas: Universidade Estadual de Campinas; 2017.

36. Vieira GS. Análise sensorial descritiva: desafios entre a metodologia e a percepção humana [tese]. Ribeirão Preto: Universidade de São Paulo; 2019.

37. Society of Sensory Professionals. [homepage on the Internet]. 2020 [cited 2021 Feb 21]. Available from: www.sensorysociety. org/Pages/default.aspx 